\title{
Commentary: Acute type A aortic dissection: Necessity is the mother of invention
}

\author{
Luca Di Marco, $\mathrm{MD},{ }^{\mathrm{a}}$ and Michele Di Mauro, $\mathrm{MD}, \mathrm{PhD}^{\mathrm{b}}$
}

\footnotetext{
From the ${ }^{\mathrm{a} C a r d i a c}$ Surgery Unit, Cardiothoracic Vascular Department, S. Orsola Hospital, University of Bologna, Bologna, Italy; and ${ }^{\mathrm{b}}$ Heart Disease Department, SS Annunziata Hospital, Chieti, Italy.

Disclosures: Authors have nothing to disclose with regard to commercial support.

Received for publication June 22, 2019; accepted for publication June 24, 2019; available ahead of print Aug 13 , 2019.

Address for reprints: Michele Di Mauro, MD, PhD, Heart Disease Department, SS Annunziata Hospital Via dei Vestini, 66100, Chieti, Italy (E-mail: mdimauro1973@gmail.com).

J Thorac Cardiovasc Surg 2020;159:e5-6

$0022-5223 / \$ 36.00$

Copyright (c) 2019 by The American Association for Thoracic Surgery

https://doi.org/10.1016/j.jtcvs.2019.06.086
}

Who of us has never heard the ancient Latin proverb "Mater artium necessitas" or the corresponding English proverb "Necessity is the mother of invention"? It means, less or more, that the main driving force for most new inventions is the necessity.

Even if the real author of this aphorism is officially unknown, it is commonly attributed to the Athenian philosopher Plato because of the translation of 1871 by the English theologian Benjamin Jowett of Plato's Republic, where in book II, according to his literal translation, the philosopher would affirm: "The true creator is necessity, which is the mother of our invention." ${ }^{1,2}$

Experience teaches us that surgical techniques often arise from the necessities that surgeons have to solve a surgical problem or to plan surgery.

Acute type A aortic dissection (ATAAD) is always a challenge for the cardiac surgeon, and this is mainly because of the technical difficulties that the surgeon deals with. In fact, despite surgery, ATAAD is still burdened by a high perioperative and intraoperative mortality and morbidity.

ATAAD complicated by cerebral malperfusion and ischemia could be another frequent and lethal event; so, often, in an emergency setting, the need arises to solve cerebral malperfusion by reestablishing an adequate bilateral cerebral perfusion.

In light of this, how should we restore the brain antegrade perfusion in case of dissection of supra-aortic vessels in ATAAD? At this point, Plato comes to the aid of surgeons..."Mater artium necessitas," Necessity is the mother of invention...with this premise, cardiac surgeons often resort to their own inventiveness to solve otherwise complex situations.

In the scenario of surgery for ATAAD, several solutions, some more standardized, such as the use of intraoperative carotid stenting, ${ }^{3}$ and others more "fanciful," such as the direct carotid perfusion before aortic repair with bilateral saphenous vein common carotid arteries anastomoses

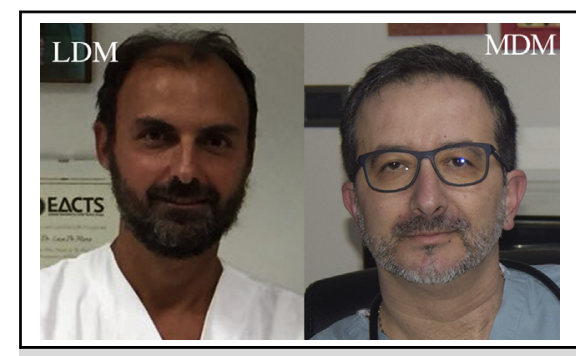

Luca Di Marco, MD, and Michele Di Mauro, MD, PhD

Central Message

Total debranching of the aortic arch with a modified FET technique could be a valid option in ATAAD with involvement of the supra-aortic vessels.

See Article page e1. through bilateral cervical incisions, ${ }^{4}$ are described to restore cerebral perfusion through the dissected carotid arteries.

The surgical technique described by Kamiya and colleagues ${ }^{5}$ refers instead to what is now a well-standardized technique in the treatment of acute and chronic dissections: the frozen elephant trunk (FET) technique. This technique, described for the first time in 1996 by 2 Japanese surgeons, Suto and colleagues ${ }^{6}$ and Kato and colleagues, ${ }^{7}$ treats complex lesions of the thoracic aorta, such as acute aortic dissection, during a single-stage procedure by placing a stent-graft in the descending thoracic aorta in an antegrade fashion directly from the arch.

Kamiya and colleagues, ${ }^{5}$ in case of involvement of both carotid arteries by the dissecting process, propose a novel FET technique with total debranching of the aortic arch to simplify and ensure complete true lumen perfusion in all supra-aortic vessels during total arch replacement.

The technique described by the authors represents a perfect practical example of what Plato claimed, "Mater artium necessitas," in the sense that the authors use a now well-standardized technique, the FET procedure, modifying it through the total debranching of supra-aortic vessels in a situation of criticality represented by the acute dissection of the supra-aortic vessels and by the need to reestablish the brain antegrade perfusion. This modified FET technique offers a valid alternative to the techniques described up to now and a possible solution in critical situations such as ATAAD. 


\section{References}

1. National Public Radio. Plato's 'Republic' Still Influential, Author Says. Talk of the Nation. August 8, 2007.

2. Plato. The Republic. Plato: His Philosophy and His Life. Available at: http://www allphilosophers.com.

3. Lentini S, Tancredi F, Benedetto F, Gaeta R. Type A aortic dissection involving the carotid arteries: carotid stenting during open aortic arch surgery. Interact Cardiovasc Thorac Surg. 2009;8:157-9.

4. Fikani AG, Kasty MT, Jebara VA. Acute type A aortic dissection with occlusion of both carotid arteries: direct carotid perfusion prior to aortic repair. J Card Surg. 2017;32:827-9.

5. Kamiya H, Nakanishi N, Ise H, Kitahara H. Total debranching hybrid total arch replacement with a novel frozen elephant trunk for acute aortic dissection type A. J Thorac Cardiovasc Surg 2020;159:e1-4.

6. Suto Y, Yasuda K, Shiiya N, Murashita T, Kawasaki M, Imamura M, et al. Stented elephant trunk procedure for an extensive aneurysm involving distal aortic arch and descending aorta. J Thorac Cardiovasc Surg. 1996;112: 1389-90.

7. Kato M, Ohnishi K, Kaneko M, Ueda T, Kishi D, Mizushima T, et al. New graftimplanting method for thoracic aortic aneurysm or dissection with a stented graft. Circulation. 1996;94(9 Suppl):II188-93.

8. Di Marco L, Leone A, Murana G, Castelli A, Alfonsi J, Di Bartolomeo R, et al. Acute type A aortic dissection: rationale and outcomes of extensive repair of the arch and distal aorta. Int $J$ Cardiol. 2018:267:145-9. 